\title{
Amino Acid Catabolism and Generation of Volatiles by Lactic Acid Bacteria
}

\author{
F. K. Tavaria, ${ }^{\star}$ S. Dahl, ${ }^{\star} †$ F. J. Carballo,‡ and F. X. Malcata* \\ *Escola Superior de Biotecnologia, Universidade Católica Portuguesa \\ Rua Dr. António Bernardino de Almeida, \\ P-4200-072 Porto, Portugal \\ †Amorim Research and Development, Rua de Meladas, \\ P.O. Box 20, P-4536-902 Mozelos, Portugal \\ ‡Departamento de Tecnología de los Alimentos, Facultad de Ciencias de Ourense, \\ E-32004 Ourense, Spain
}

\section{ABSTRACT}

Twelve isolates of lactic acid bacteria, belonging to the Lactobacillus, Lactococcus, Leuconostoc, and Enterococcus genera, were previously isolated from 180d-old Serra da Estrela cheese, a traditional Portuguese cheese manufactured from raw milk and coagulated with a plant rennet. These isolates were subsequently tested for their ability to catabolize free amino acids, when incubated independently with each amino acid in free form or with a mixture thereof. Attempts were made in both situations to correlate the rates of free amino acid uptake with the numbers of viable cells. When incubated individually, leucine, valine, glycine, aspartic acid, serine, threonine, lysine, glutamic acid, and alanine were degraded by all strains considered; arginine tended to build up, probably because of transamination of other amino acids. When incubated together, the degradation of free amino acids by each strain was dependent on $\mathrm{pH}$ (with an optimum $\mathrm{pH}$ around 6.0). The volatiles detected in ripened Serra da Estrela cheese originated mainly from leucine, phenylalanine, alanine, and valine, whereas in vitro they originated mainly from valine, phenylalanine, serine, leucine, alanine, and threonine. The wild strains tested offer a great potential for flavor generation, which might justify their inclusion in a tentative starter/nonstarter culture for that and similar cheeses.

(Key words: flavor, catabolism, starter cultures, cheese)

Abbreviation key: LAB = lactic acid bacteria, FAA = free amino acids, $\mathbf{~} \mathbf{g} / \mathbf{1 0 0} \mathbf{g}_{\mathbf{D M}}=$ milligram per 100 gram of dry matter, PCA = principal component analysis.

Received January 22, 2002.

Accepted April 27, 2002.

Corresponding author: F.X. Malcata; e-mail: xmalcata@esb.ucp.pt.

\section{INTRODUCTION}

Most flavor notes that specifically characterize each type of cheese develop during ripening, due to the presence of a number of actively metabolizing microrganisms (with starter and nonstarter roles), as well as enzymes secreted by these microorganisms (or released therefrom after lysis) coupled with enzymes indigenous in milk (or added thereto as part of the rennet) (Fox and Law, 1991). The main sapid compounds in cheese are produced through the primary reactions of glycolysis, lipolysis, and proteolysis. Such compounds, especially free amino acids (FAA), do often undergo further transformation via several secondary reactions which are still poorly known (Fox and Wallace, 1997), to eventually yield aroma compounds. Consequently, the actual concentration of the former compounds in cheese has been used as a basis for the calculation of ripening indices, as it usually correlates well with flavor intensity.

The dominant FAA in Cheddar cheese are Leu, Glu, and Lys (Wood et al., 1985), although variations in their relative amounts have been reported by other authors (Broome et al., 1990). In European traditional cheeses produced from raw ewe's and/or goat's milk (e.g., Manchego cheese), the amounts of almost every type of FAA increase with ripening time (Ordónez and Burgos, 1980). In Idiazabal cheese, increases in the total FAA concentration from $200 \mathrm{mg}$ per $100 \mathrm{~g}$ of DM (mg/100 $\mathbf{g}_{\text {DM }}$ ) in 1-d-old to $1300 \mathrm{mg} / 100 \mathrm{~g}_{\mathrm{DM}}$ in 12 -mo-old cheeses have been reported (Barcina et al., 1995); the dominant FAA found were Glu, Val, Leu, and Phe. Studies pertaining to Portuguese traditional cheeses, e.g., Picante da Beira Baixa, have also pointed at increases of total FAA as ripening time elapses, say from approximately 30 to $54 \mathrm{mg} / 100 \mathrm{~g}_{\mathrm{DM}}$ at $0 \mathrm{~d}$ to 1330 to $1940 \mathrm{mg} / 100 \mathrm{~g}$ DM by $180 \mathrm{~d}$ (Freitas et al., 1998); the dominant FAA were, in this case, Val, Leu, and Phe.

Lactic acid bacteria (LAB) are nutritionally fastidious microorganisms, which are, nevertheless, able to 
hydrolyze milk peptides down to FAA. Amino acid catabolism produces, in turn, a number of compounds, including ammonia, amines, aldehydes, phenols, indole and alcohols, which contribute as a whole to cheese flavor (Urbach, 1995); however, the roles played by each species (or even genus) of LAB in terms of those biochemical routes are not yet fully understood. There are usually three recognizable steps in this complex process: the first one pertains to such reactions as decarboxylation, deamination, transamination, desulfuration, and hydrolysis of side-chains; the second one involves conversion of the resulting compounds (mainly amines and $\alpha$-ketoacids), as well as some FAA themselves, to aldehydes affected by deaminases; and the third stage corresponds to reduction of aldehydes to alcohols, or their oxidation to carboxylic acids. Sulfurcontaining FAA may undergo specific chemical reactions, which are responsible mainly for the generation of methanethiol and a few other sulfur derivatives.

Volatiles evolving from the metabolism of FAA do apparently contribute to the final organoleptic characteristics of ripened cheeses. Extensive reviews (Urbach, 1995; Fox and Wallace, 1997) are available pertaining to the profile of volatiles in many cheese varieties; some studies have even focused on microbial-mediated volatile components, derived from individual FAA, in homogeneous model systems. Improved mass spectrometric methods of detection after resolution by gas chromatography can be applied to the analysis of volatiles in cheese extracts; these methods have contributed considerably to the accumulated body of knowledge encompassing flavor components (Bosset and Gauch, 1993; Esteban et al., 1996). Nevertheless, the relationship between the numbers of viable microorganisms that may produce such volatiles and the concentration of said volatiles is not trivial. Efforts to unfold such a relation require, as a primary approach, that the metabolic potential of each microbial species be investigated independently in a model system.

In addition to the aforementioned limitation, studies on Portuguese traditional cheeses, known for their unique bouquet, are even scarcer. A plethora of new knowledge is to be gained because those cheeses are produced from raw milk and coagulated with an enzyme extracted from the flowers of wild thistle (Cynara cardunculus), which results in a heterogeneous final product with obvious commercial limitations. Note that Serra da Estrela cheese is the most famous cheese in Portugal, with the highest economic and social relevance among all Portuguese cheeses. Several other semisoft cheeses produced in Spain also share the milk and rennet feedstock uniqueness described above, so the tentative starter/nonstarter culture eventually to be developed for Serra da Estrela cheese may likely meet with success in the manufacture of the latter cheeses.

Therefore, our study intended to shed light into this particular area by investigating the catalytic potential of LAB that had been previously isolated from Serra da Estrela cheese. For such goal, a twofold approach was followed, based on either individual FAA or all FAA in a cocktail, at various $\mathrm{pH}$ values (4.5, 6.0, and 7.5). Curdled milk was also tested with four of the isolates in order to approach cheese-like conditions.

\section{MATERIALS AND METHODS}

\section{Microorganisms Employed}

Twelve colonies of LAB, previously isolated from 180d-old Serra da Estrela cheese, were used in this study. Three of them, namely ESB 321, ESB 322, and ESB 323, were isolated from Rogosa agar (Merck, Darmstadt, Germany) and identified by SDS-PAGE as Lactobacillus paracasei ssp. paracasei, Lactobacillus brevis and Lactobacillus rhamnosus / plantarum, respectively. Isolates ESB 326, ESB 327, and ESB 330 were isolated from Mayeux, Sandine, and Elliker (MSE) agar (Biokar, Beauvais, France) and identified by SDS-PAGE as Leuconostoc mesenteroides ssp. dextranicum (first two) and Leuconostoc lactis (last one). From M17 agar, the following species (identified by SDS-PAGE) were recovered: L. lactis ssp. lactis (ESB 331), L. brevis (ESB 332), and L. lactis (ESB 333). Finally, from KF-Streptococcus agar (Merck), the isolates were identified by SDS-PAGE as Enterococcus faecium (ESB 337 and 338) and E. faecalis ssp. liquefaciens (ESB 340). The chemotaxonomical method employed, based on SDS-PAGE of disrupted cultures followed by dendogram grouping, was described to full length by Kersters (1985) and Jackman (1985).

\section{Buffer Experiments}

Selected isolates, kept on MRS (Lactobacillus and Leuconostoc) or M17 (Lactococcus and Enterococcus) agar slants, were subcultured in MRS or M17 (Merck) broth as appropriate (cultures were thus maintained in general purpose, rather than selective media, as regular practice in applied microbiology). They were then inoculated at $2 \%$ in $100 \mathrm{~mL}$ of fresh MRS broth and allowed to reach the stationary phase $(\sim 16 \mathrm{~h})$; after this, they were centrifuged at $12,000 \times g$ for 20 min using a Sorvall Centrifuge RC5 (Wilmington, DL) and washed twice with phosphate buffer ( $\mathrm{pH}$ 6.0). The pellet was resuspended in $56 \mathrm{~mL}$ of phosphate buffer $(50 \mathrm{mM}, \mathrm{pH}$ 6.0), added to $44 \mathrm{~mL}$ of buffer containing $0.02 \%$ (wt/ vol) of the desired FAA, and incubated at $30^{\circ} \mathrm{C}$ for up to $7 \mathrm{~d}$. The phosphate buffer added to the washed cells 
contained either a single FAA or a mixture of 16 FAA $(25 \mathrm{mM})$, without or with added $\alpha$-ketoglutarate (10 $\mathrm{m} M$ ) (Sigma Chemical, St. Louis, MO).

\section{Curdled Milk Experiments}

Sterilized sheep's milk curdled with $C$. cardunculus (aqueous crude extract, containing $0.3 \mathrm{~g} / \mathrm{L}$ of dry flowers and $12 \mathrm{~g} / \mathrm{L}$ of $\mathrm{NaCl}$ ) was inoculated $(2 \%$ of washed cell suspension, prepared as described above) with each of the four isolates individually (ESB 321, ESB 327, ESB 331, and ESB 338), to follow FAA degradation in the absence or presence of added $0.025 \mathrm{~mol} / \mathrm{L}$ of $\alpha$-ketoglutarate. Samples were incubated at $30^{\circ} \mathrm{C}$ (Lactobacillus and Leuconostoc) or $37^{\circ} \mathrm{C}$ (Lactococcus and Enterococcus). The concentration of the FAA remaining and the number of viable cells were monitored at the following time intervals: 0, 15, 30, and $45 \mathrm{~d}$. Sterilized sheep's milk, curdled with $C$. cardunculus and not inoculated at all, was used as control.

\section{Microbiological Analyses}

Samples $(1 \mathrm{ml})$ from the buffer experiments and the curdled milk experiments were taken at selected time intervals, say $0,3,5$, and $7 \mathrm{~d}$, and $0,15,30$, and $45 \mathrm{~d}$, respectively, and decimally diluted in sterile $0.1 \%$ (wt/ vol) peptone water (Sigma). They were then plated in duplicate on MRS agar, to assay for: Lactobacillus, as standard practice; and for Leuconostoc, following the successful results by Macedo et al. (1995) (results not shown have been generated using M17-a medium recommended for lactic streptococci-but no significant differences were found); and on M17 agar, to assay for Lactococcus and Enterococcus. In both cases, the spread- plate technique was used. The plates were incubated anaerobically (Lactobacillus and Lactococcus) and aerobically (Leuconostoc and Enterococcus), at $30^{\circ} \mathrm{C}$ for 3 to $4 \mathrm{~d}$ (Tavaria and Malcata, 1998); after this time, the colonies were duly counted.

\section{Analysis of Free Amino Acids}

In experiments where single FAA were used in each incubation, samples $(1.0 \mathrm{ml})$, previously cleared of cells and cell debris by centrifugation for $15 \mathrm{~min}$ at $3,000 \times$ $g$, were added to $2 \mathrm{ml}$ of $\mathrm{Cd}$-ninhydrin reagent; this reagent was prepared by first dissolving $0.8 \mathrm{~g}$ of ninhydrin (Sigma) in a mixture of $80 \mathrm{ml}$ of absolute ethanol (Romil, Loughborough, UK) and $10 \mathrm{ml}$ of acetic acid (Pronalab, Lisbon, Portugal), followed by addition of 1 $\mathrm{g}$ of $\mathrm{CdCl}_{2}$ (Sigma) dissolved in $1 \mathrm{ml}$ of distilled water. The mixture was heated at $84^{\circ} \mathrm{C}$ for $5 \mathrm{~min}$ and then cooled to room temperature; absorbance was read at
$507 \mathrm{~nm}$, except for proline for which absorbance was read at $440 \mathrm{~nm}$ (Folkertsma and Fox, 1992). A calibration curve was constructed for each FAA. To determine FAA in samples containing a mixture thereof, either in buffer or in curdled milk, $0.2 \mathrm{ml}$ of the sample was taken, centrifuged for $15 \mathrm{~min}$ at $3,000 \times g$, and mixed with $200 \mu \mathrm{l}$ of 9-fluorenylethyl-chloroformate, FLEC (Sigma-Aldrich, Steinheim, Germany) for $5 \mathrm{~min}$. The excess reagent was eliminated by addition of $200 \mu \mathrm{ml}$ of $2 M$ amantadine (Sigma-Aldrich) in acetone. The mixture was then centrifuged for $15 \mathrm{~min}$ at 3,000 $\times \mathrm{g}$ to remove the precipitate; $5 \mu \mathrm{l}$ of the supernatant was finally injected in the HPLC system (LaChrom, Merck, Germany) using an automatic injection system. Separation was accomplished at $30^{\circ} \mathrm{C}$ via a ChromSep Microsphere $\mathrm{C}_{18}$ column $(50 \mathrm{~mm} \times 4.6 \mathrm{~mm} \times 4 \mu \mathrm{m})$, and detection was carried out using UV absorption at 254 $\mathrm{nm}$. The flow rate was $2.0 \mathrm{ml} / \mathrm{min}$; the mobile phases were: acetonitrile (A), methanol (B) and buffer (3 $\mathrm{ml}$ of acetic acid and $1 \mathrm{ml}$ of $\mathrm{NH}_{4} \mathrm{OH} / \mathrm{L}$ of ultrapure water) (C). The following gradient sequence was used: A: $10 \%$ for all times; B: 15, 30, 45, 60, and $75 \%$ at $0,2,5,9$, and $14 \mathrm{~min}$, respectively; C: 75, 60, 45, 30, and $15 \mathrm{~min}$ at $0,2,5,9$, and $14 \mathrm{~min}$, respectively. [AQ: Verify wording and insertion of (Table 1).]

Calibration was previously done by injecting standard solutions of chromatographic grade FAA (Sigma), at several concentrations.

\section{Analysis of Volatiles}

Volatiles resulting from in vitro FAA catabolism were recovered using solid-phase microextraction, a technique pioneered by Chin et al. (1996). Headspace sampling was carried out using $\mathrm{N}_{2}$ to carry the volatiles released from the sample onto a polyacrylate fiber, which they were eventually adsorbed to. Soon after this, adsorbed volatiles were desorbed via a thermal shock up to the temperature of the injector in the gas chromatograph (Thermo Quest, Trace GC 2000 Series; Finnigan, San Jose, CA) in splitless mode. Separation was achieved in a DB-Wax column $(60 \mathrm{~m} \times 0.32 \mathrm{~mm} \times 0.25$ $\mu \mathrm{m}$ ) from J\&W Scientific (Folsom, CA). Gas chromatography-mass spectrometry was carried out with the same column using a GCQ MS detector from Thermo Quest (Finnigan). The oven temperature was maintained at the initial value of $35^{\circ} \mathrm{C}$ for $2 \mathrm{~min}$, then increased to $175^{\circ} \mathrm{C}$ (at $4^{\circ} \mathrm{C} / \mathrm{min}$ ), and finally increased to $225^{\circ} \mathrm{C}$ (at $10^{\circ} \mathrm{C} / \mathrm{min}$ ). System control, as well as data acquisition and analysis, were all accomplished with data processing and analysis software from Finnigan.

\section{Statistical Analyses}

ANOVA was conducted, at the 5\% level of significance, for the FAA concentration (curdled milk experi- 
Table 1. Percent degradation of FAA, after individual incubation at $30^{\circ} \mathrm{C}$ for $7 \mathrm{~d}$ with selected strains of LAB. Negative values indicate increases in concentration.

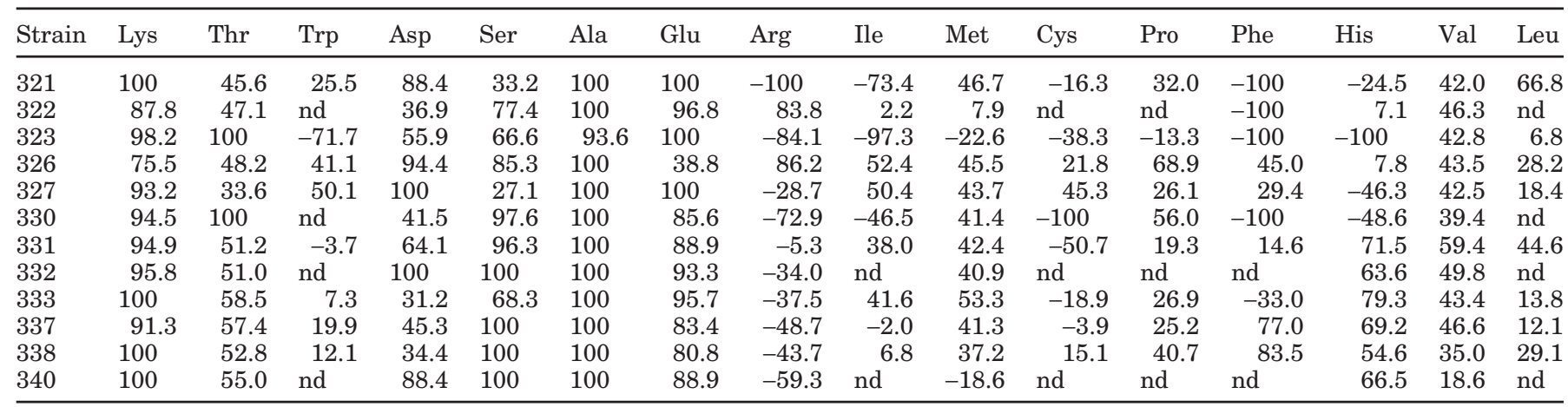

nd $=$ not determined.

ments), with addition of $\alpha$-ketoglutarate, incubation time and isolate inoculated as main factors. Principal component analysis (PCA) was also applied to the same data set. All statistical analyses were carried out using Statistica for Windows v. 5.1, StatSoft, 1996.

\section{RESULTS AND DISCUSSION}

\section{Metabolism of Free Amino Acids Independently}

The rate of degradation of every single FAA was monitored via incubation of individual FAA in phosphate buffer with selected wild strains, previously isolated from ripened Serra da Estrela cheese. It was somewhat expected that these isolates would preferably degrade those FAA most abundant in that cheese (Leu, Val, Glu, and Lys) at the later stages of maturation. However, this was not the case of our experimental observations. In fact, some of the less prevalent FAA (e.g., Ser) were totally degraded by some isolates. From the major FAA prevalent in Serra da Estrela cheese by 180 d of ripening, and which were individually subject to action by each of the selected isolates (Table 1), it can be concluded that Lys and Glu were completely degraded by all. Valine was degraded up to $59.4 \%$, whereas Leu was degraded up to $66.8 \%$. In what pertains to the other FAA, Asp was substantially degraded by all strains (from 31 to up to 100\%), as well as Ser (from 27 to up to $100 \%$ ), Thr (from 33.5 to up to $100 \%$ ), and Ala (from 93.6 to up to $100 \%$ ). The concentration of Arg tended to build up in 10 out of 12 isolates. A clear trend could not be found for these strains toward Trp, Ile, Met, Cys, and His. When studying FAA catabolism by four strains of Propionibacterium, Brendehaug and Langsrud (1985) also reported large differences among strains in their ability to degrade FAA.

\section{Metabolism of Free Amino Acids in Cocktail}

Figure 1 represents amino acid degradation by four of the isolates considered in this study, at various $\mathrm{pH}$ values $(4.5,6.0$, and 7.5). When all FAA were simultaneously incubated in solution, the observed capacity of each microbial isolate to metabolize them was greatly dependent on $\mathrm{pH}$. At the highest $\mathrm{pH}$ tested (i.e., 7.5), the catalytic power reflected mainly in transamination reactions; Gln and Phe increased their concentration with time when incubated with all 12 isolates, and Met increased in concentration with eight isolates, whereas Ser, Arg, and Ile decreased. At $\mathrm{pH}$ 4.5, Phe accumulated, while Thr, Gly, Met, Arg, Pro, Asn, and Asp were depleted. At pH 6.0, Asn, Asp, Thr, Leu, Pro, Met, and Glu were degraded, whereas Ala built up; Ser, Ile, and Arg were completely degraded at this $\mathrm{pH}$. Overall, most degradation took place at $\mathrm{pH} 6.0$, which lies in the vicinity of the $\mathrm{pH}$ optima for most microbial enzymes (and is also close to the physiological $\mathrm{pH}$ ). In addition, the FAA most extensively degraded are those possessing a hydrophilic character (i.e., Glu, Gln, Asn, Asp, Lys, and Arg), and which therefore dissolve better in water-based buffers. It is interesting to note that Pro, Val and Leu, all highly hydrophobic FAA, were also extensively degraded, perhaps owing to their predominance in the pool of AA residues accounted for by ewe's caseins in Serra da Estrela cheese.

The effect of $\alpha$-ketoglutarate was also evaluated at pH 6.0 (Fig. 2); this compound was included as it plays an important role in the initial steps of transamination (Tamman et al., 2000). The effect of the addition of $\alpha$ ketoglutarate $(10 \mathrm{mM})$ was dependent on the isolate in question. As suggested by Yvon et al. (1998), the differences found in the degradation rates using different starters had to do with the concentration of substrate FAA (including glutamate). Furthermore, they concluded that FAA degradation depends also on the 

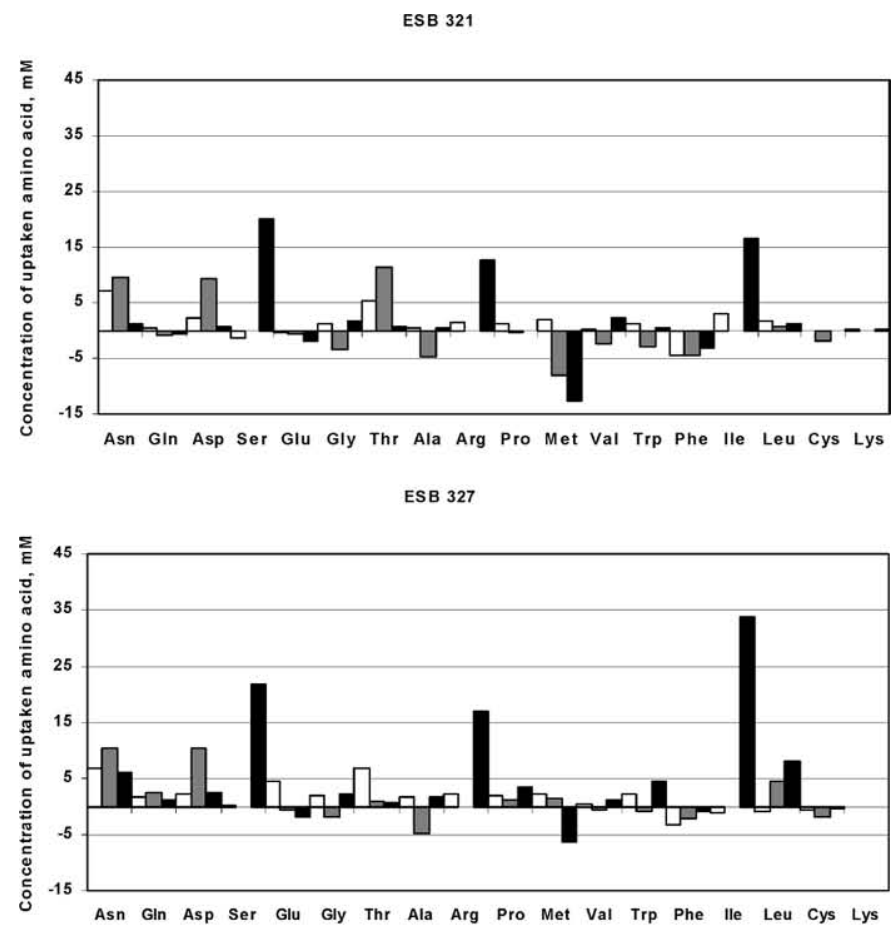

ESB 331
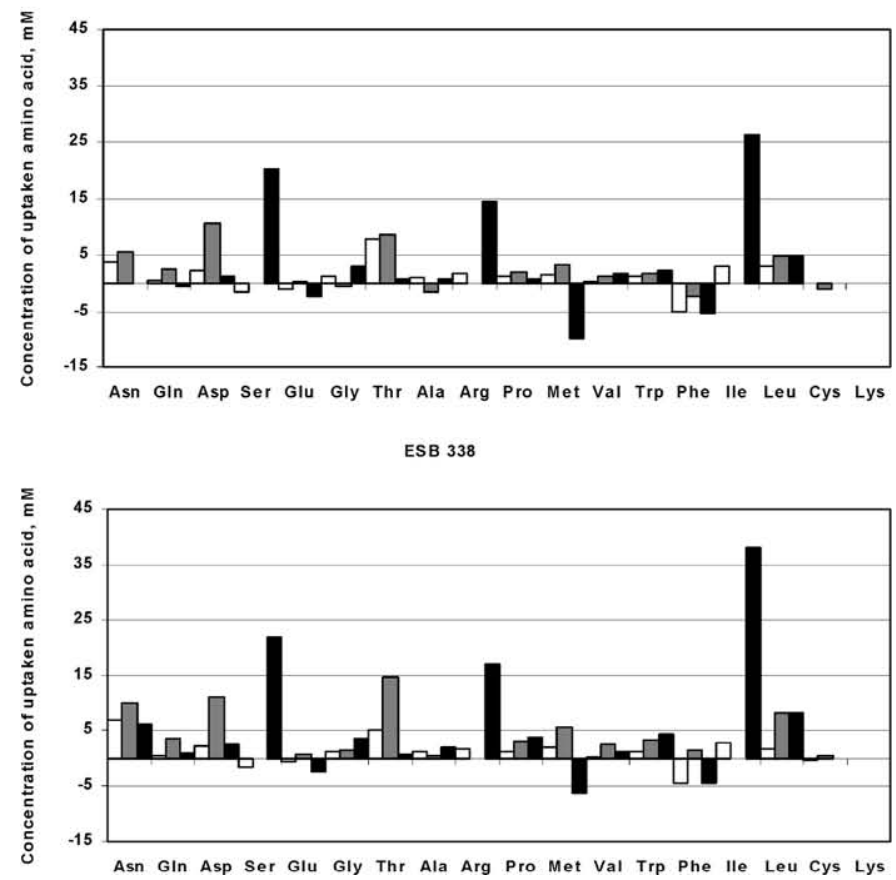

Figure 1. In vitro degradation of free amino acids in cocktail, brought about by four isolates (ESB $321=$ Lactobacillus paracase ssp. paracasei, ESB 327 = Leuconostoc mesenteroides ssp. dextranicum, ESB 331 = Lactococcus lactis ssp. lactis, and ESB $338=$ Enterococcus faecium) from Serra da Estrela cheese, by $7 \mathrm{~d}$ of incubation at several pH values, viz. 4.5 ( $\square$ ), 6.0 (lightly shaded bar) and 7.5 (ロ). aminotransferase activities of the various starters. When isolate ESB 331 was used, it promoted degradation of almost all FAA. No observable increase in FAA uptake was detected in the presence of $\alpha$-ketoglutarate when isolates ESB 323 and ESB 338 were used, except for Phe (isolate 323) and Glu (isolate 338). When isolate ESB 330 was used, the addition of $\alpha$-ketoglutarate promoted uptake of Thr, Pro, Leu, Glu, and Trp. These distinct observations may be attributable to metabolic differences between the genera tested. Substrate utilization by nonstarter LAB was also studied by Tammam et al. (2000) using Biolog MT microplates; these authors confirmed that many of those microrganisms have the ability to generate energy from FAA catabolism, but only in the presence of exogenously supplied $\alpha$-ketoglutarate, hence confirming the findings by Yvon et al. (1998). Similarly to what happened in individual FAA incubations, Glu and Ala were the most degraded FAA (see Figure 2), while Thr and Met tended to build up (i.e., negative values on the y-axis) in this system. The viable numbers remained relatively high during the course of the experiment at $\mathrm{pH}$ 7.5: initially (i.e., right after inoculation) in the log range of 9.0 to $9.5 \mathrm{CFU} /$ $\mathrm{ml}$, and finally (i.e., by $7 \mathrm{~d}$ ) in the log range 8.8 to 9.2 , for all strains. At $\mathrm{pH} 4.5$ and 6.0, the log viable numbers per milliliter dropped slightly from 8.8 to 7.0 in the same time frame. Autolytic experiments (data not shown) encompassing the four isolates (ESB 321, ESB 327, ESB 331, and ESB 338) showed that lysis in general occurred later at more extreme $\mathrm{pH}$ values; this observation was quite apparent for isolate ESB 338. At $\mathrm{pH}$ 6.0, isolates ESB 327 and 331 lysed earlier than the other two, which might explain why isolate ESB 327 produced the largest number of volatiles via FAA catabolism (Table 4).

The enzymatic conversion of FAA is a rate-limiting factor in the development of flavor compounds during cheese maturation (Christensen and Reineccius, 1995). As demonstrated by Wallace and Fox (1997), the addition of FAA to Cheddar cheese did not result in significant flavor development. Yvon et al. (1997) suggested that transamination is the first step in aromatic FAA degradation by lactococci, since no oxidative deamination or decarboxylation was detected. Aminotransferases, the enzymes able to catalyze these reactions, are also responsible for the uptake of Leu and Met. Gummalla and Broadbent (1999), in a study on Trp catabolism by lactobacilli, indicated that these bacteria catabolize Trp to indole-3-lactic acid through successive transamination reactions. When studying L-Phe catabolism by microorganisms originated in cheese, Lee and Richard (1984) found that phenylpyruvic acid is an intermediate in bacteria, although yeasts are able to directly produce phenylethyl alcohol from Phe; hence, 

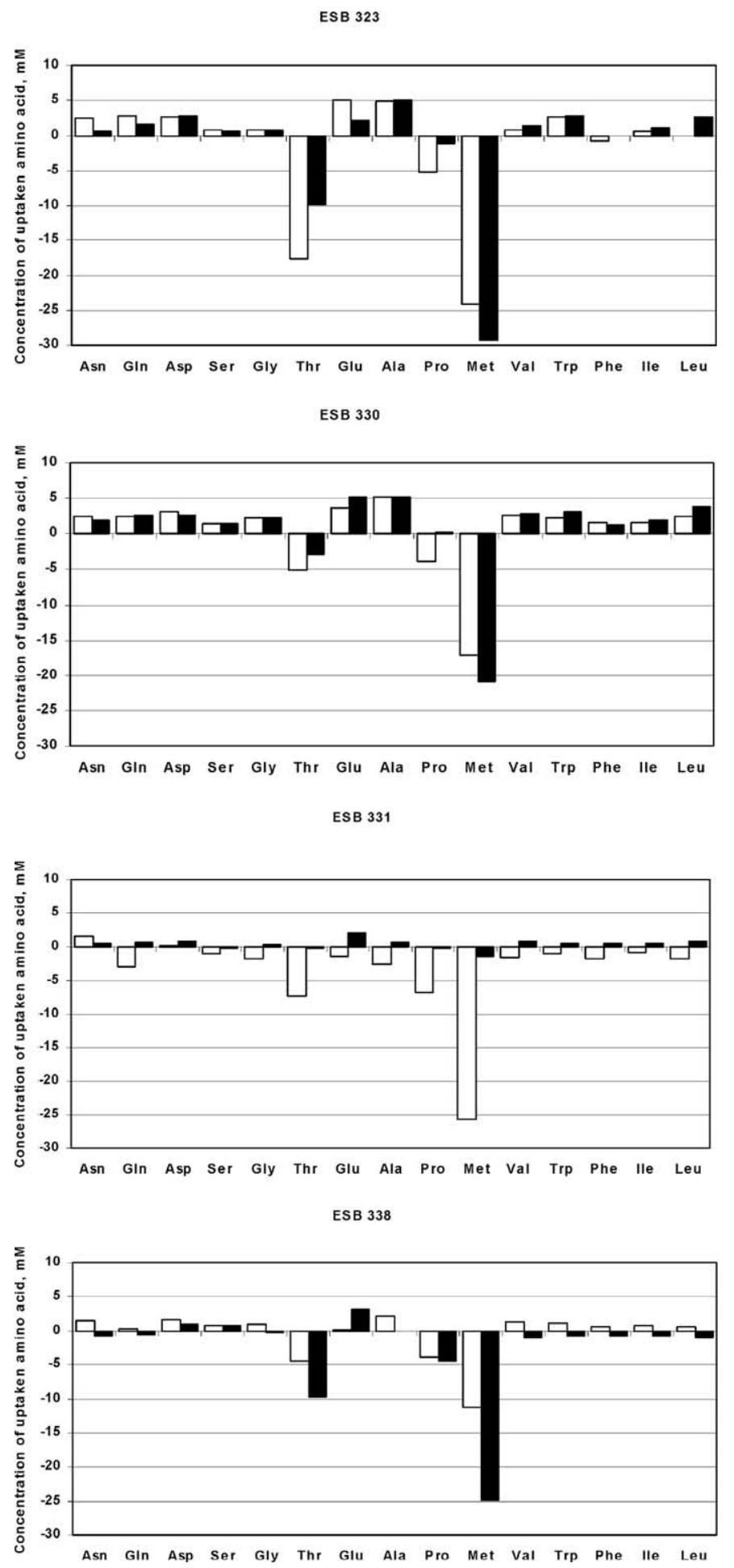

Figure 2. In vitro degradation of free amino acids in cocktail $(\mathrm{pH}$ 6.0), brought about by four isolates (ESB 323 Lactobacillus rhamnosus/plantarum, ESB 330 Leuconostoc lactis, ESB 331 Lactococcus lactis ssp. lactis, and ESB 338 Enterococcus faecium) from Serra da Estrela cheese, by $7 \mathrm{~d}$ of incubation in the absence $(\square)$ or in the presence (ם) of $\alpha$-ketoglutarate. transamination (leading to formation of the corresponding keto acid) would in fact be the first step in Phe catabolism.

\section{Metabolism of Free Amino Acids in Curdled Milk}

Table 2 depicts the amount of FAA remaining in curdled milk after $45 \mathrm{~d}$ of incubation with each of the four isolates tested, and corresponding standard deviation (no significant differences were found between the samples taken at 0,15 , and $30 \mathrm{~d}$ ). Analysis of variance, at the $5 \%$ level of significance, using isolate, incubation time, and addition of $\alpha$-ketoglutarate as main factors, allowed one to conclude that those factors were always statistically significant toward degradation of all FAA, except Gln, Glu, Met, and Lys. For Gln and Glu, the addition of $\alpha$-ketoglutarate was not significant, whereas the amount of Glu, Met, and Lys degraded was not dependent on the isolate used as inoculum. Interestingly, Glu was again among the most degraded FAA in this system, whereas Ala (unlike what happens in the buffer system) was one of the least degraded FAA. The log numbers of viable cells/ml remained essentially constant (ca. 8.5) from the time of inoculation up to $45 \mathrm{~d}$.

Principal component analysis of our set of data led to identification of four clear clusters (Figure 3): one comprising the 0 -d samples (with and without $\alpha$-ketoglutarate) (cluster 1), a second one comprising the 30and 45-d samples with $\alpha$-ketoglutarate (cluster 2), a third one comprising the 15 -d samples with $\alpha$-ketoglutarate added (cluster 3), and the last one comprising the 15-, 30-, and 45-d samples without $\alpha$-ketoglutarate (cluster 4). Over $85 \%$ of the total variance was accounted for by the first four principal components (PC1, PC2, PC3, and PC4). The correlation matrix shows that all samples from cluster 1 are significantly (and negatively) correlated with factor 2, PC2; Pro and Lys are, on the other hand, significantly correlated (positively and negatively, respectively) with this factor. Figure 4 shows the FAA distribution along PC1 and PC2 for all samples: Asn, Asp, Thr, Ala, Met, Val, and Ile are negatively correlated with PC1 and with samples from cluster 4, meaning that samples without $\alpha$-ketoglutarate yielded high amounts of these FAA (therefore, having degraded them to a lesser extent), unlike the samples in cluster 2 (located in the diagram in an opposed position), which are those with $\alpha$-ketoglutarate and lower amounts of the aforementioned FAA; Pro and Lys correlated with PC2 and with samples from cluster 1, thus indicating that these samples had high amounts of Lys and Pro. The highest score on PC1 was obtained by Glu; this FAA, which may be produced by the action of rennet, is predominant in various types of cheese, and is known to enhance cheese flavor. 
Table 2. Average ( \pm standard deviation) of concentration $(\mathrm{mM})$ of FAA remaining in curdled milk, after incubation at $10^{\circ} \mathrm{C}$ for $45 \mathrm{~d}$.

\begin{tabular}{|c|c|c|c|c|c|c|c|c|c|c|}
\hline \multirow[b]{3}{*}{ FAA } & \multicolumn{10}{|c|}{ Curdled milk incubated with one isolate } \\
\hline & \multicolumn{5}{|c|}{ Without addition of $\alpha$-ketoglutarate } & \multicolumn{5}{|c|}{ With addition of $\alpha$-ketoglutarate } \\
\hline & Control & 321 & 327 & 331 & 338 & Control & 321 & 327 & 321 & 338 \\
\hline Asn & 0.35 & $0.29 \pm 0.01$ & $0.30 \pm 0.04$ & $0.31 \pm 0.02$ & $0.35 \pm 0.01$ & 0.58 & $0.28 \pm 0.00$ & $0.31 \pm 0.02$ & $0.29 \pm 0.02$ & $0.33 \pm 0.01$ \\
\hline Gln & 0.25 & $0.34 \pm 0.01$ & $0.35 \pm 0.05$ & $0.38 \pm 0.03$ & $0.50 \pm 0.16$ & 0.26 & $0.32 \pm 0.01$ & $0.37 \pm 0.03$ & $0.34 \pm 0.03$ & $0.40 \pm 0.02$ \\
\hline Asp & 0.57 & $0.00 \pm 0.00$ & $0.00 \pm 0.00$ & $0.00 \pm 0.00$ & $0.00 \pm 0.00$ & 0.65 & $0.00 \pm 0.00$ & $0.00 \pm 0.00$ & $0.00 \pm 0.00$ & $0.00 \pm 0.00$ \\
\hline Ser & 0.44 & $0.00 \pm 0.00$ & $0.00 \pm 0.00$ & $0.00 \pm 0.00$ & $0.00 \pm 0.00$ & 0.39 & $0.00 \pm 0.00$ & $0.00 \pm 0.00$ & $0.00 \pm 0.00$ & $0.00 \pm 0.00$ \\
\hline Ala & 2.49 & $2.04 \pm 1.84$ & $2.83 \pm 2.28$ & $2.63 \pm 1.80$ & $4.12 \pm 1.68$ & 17.44 & $1.10 \pm 0.50$ & $3.89 \pm 0.78$ & $1.29 \pm 0.10$ & $3.42 \pm 0.69$ \\
\hline Pro & 0.39 & $0.41 \pm 0.01$ & $0.42 \pm 0.01$ & $0.41 \pm 0.00$ & $0.39 \pm 0.03$ & 0.40 & $0.40 \pm 0.01$ & $0.41 \pm 0.00$ & $0.42 \pm 0.01$ & $0.41 \pm 0.00$ \\
\hline Met & 1.56 & $0.40 \pm 0.04$ & $0.58 \pm 0.07$ & $0.60 \pm 0.06$ & $0.72 \pm 0.01$ & 14.19 & $0.42 \pm 0.05$ & $0.53 \pm 0.14$ & $0.58 \pm 0.08$ & $0.63 \pm 0.11$ \\
\hline Val & 0.36 & $0.33 \pm 0.01$ & $0.35 \pm 0.01$ & $0.33 \pm 0.01$ & $0.35 \pm 0.07$ & 0.47 & $0.32 \pm 0.00$ & $0.34 \pm 0.00$ & $0.34 \pm 0.03$ & $0.36 \pm 0.05$ \\
\hline Phe & 0.41 & $0.38 \pm 0.00$ & $0.37 \pm 0.00$ & $0.38 \pm 0.01$ & $0.37 \pm 0.02$ & 0.39 & $0.37 \pm 0.00$ & $0.38 \pm 0.00$ & $0.38 \pm 0.00$ & $0.38 \pm 0.01$ \\
\hline Ile & 0.41 & $0.39 \pm 0.06$ & $0.40 \pm 0.06$ & $0.37 \pm 0.02$ & $0.42 \pm 0.02$ & 0.60 & $0.36 \pm 0.02$ & $0.44 \pm 0.01$ & $0.36 \pm 0.00$ & $0.41 \pm 0.03$ \\
\hline Leu & 0.33 & $0.34 \pm 0.01$ & $0.34 \pm 0.01$ & $0.34 \pm 0.00$ & $0.34 \pm 0.01$ & 0.40 & $0.34 \pm 0.01$ & $0.34 \pm 0.01$ & $0.34 \pm 0.00$ & $0.34 \pm 0.00$ \\
\hline
\end{tabular}

\section{Production of Volatile Compounds from FAA}

Volatiles present in ripened cheese are shown in Table 3. The most abundant volatile compound in Serra da Estrela cheese is 3-methylbutyric acid (Dahl et al., 2000 ), which is the product of metabolic breakdown of Leu, a rather abundant FAA in that cheese. However, the profile of the FAA pool in cheese derived from casein does not apparently constrain the pattern of volatiles generated: remember that the most abundant FAA in ripened Serra da Estrela cheese are Leu, Val, Glu, and Lys, but the volatile products found only in cheese (Table 3) do originate from reactions that depart from Ala, Glu, Gly, Asp, Leu, Lys, Phe, and Tyr as substrates.

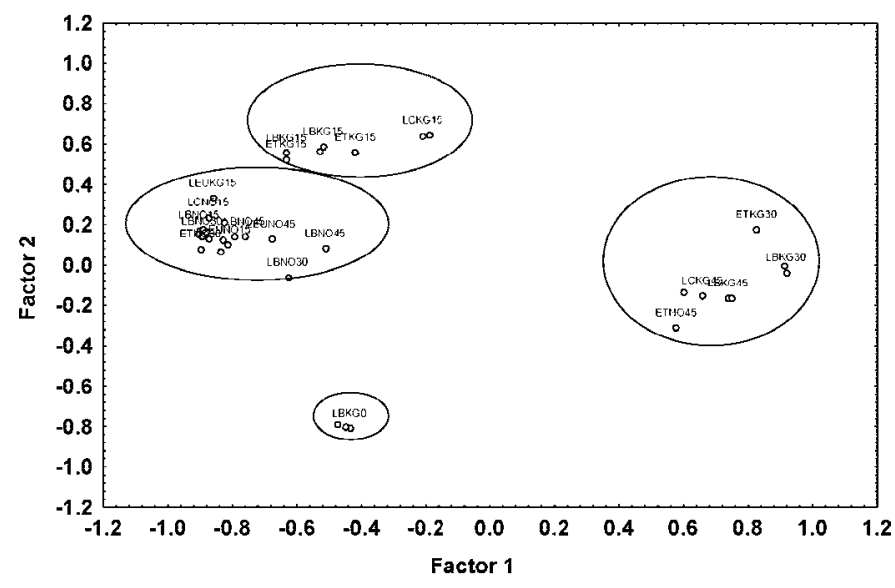

Figure 3. Principal component analysis plot, showing the distribution of the samples along factors 1 and 2. Abbreviations indicate bacterial genus, addition (KG) or not (NO) of $\alpha$-ketoglutarate, and period of incubation in days (e.g., LBKG0 $=$ Lactobacillus, with $\alpha$ ketoglutarate, $0 \mathrm{~d}$ of incubation; LCNO15 = Lactococcus, without added $\alpha$-ketoglutarate, $15 \mathrm{~d}$ of incubation). ET = Enterococcus, LEU = Leuconostoc.
The volatiles generated in vitro by catabolism of the FAA cocktails, at $\mathrm{pH} 6.0$ and by $7 \mathrm{~d}$ of incubation, by each of the four bacterial genera are listed in Table 4 . Considering in detail the (known) molecular structures of such volatiles, and comparing with previous work by several authors (e.g., Engels and Visser, 1994; Wallace and Fox, 1997), one can draw a few conclusions on their putative precursors. First, it seems that these volatiles build-up via decarboxylation, deamination, transamination, and Strecker degradation reactions undergone by FAA. Subsequent processes encompass reduction (or oxidation) of Strecker degradation products, rearrangements, and cyclizations, as well as reactions between secondary products of FAA catabolism (Molimard and Spinnler, 1996). Furthermore, compounds that are typically generated in cheese were not produced by our isolates in vitro, such as ethanol, 1-propanol, butyl lactate, 4-methylvaleric acid, and phenylethyl alcohol. These pieces of evidence are obviously

Table 3. Volatile compounds present in Serra da Estrela cheese by $180 \mathrm{~d}$ of ripening.

\begin{tabular}{ll}
\hline & Putative \\
Compound & precursor \\
\hline Ethanol & Ala \\
Propionic acid & Ala \\
1-Propanol & Glu \\
Acetic acid & Gly \\
3-Methyl-1-butanol & Leu \\
3-Methyl-butyric acid & Leu \\
4-Methylvaleric acid & Leu \\
Phenylethyl alcohol & Phe \\
Phenylacetic acid ethylester & Phe \\
Phenol & Tyr \\
Hexanoic acid & Lys \\
Butyl lactate & Asp \\
Isopropyl isobutyrate & Val \\
2-Methylpropionic acid & Val \\
\hline
\end{tabular}


Table 4. Volatile compounds present in the FAA cocktail, inoculated with the various genera studied and incubated at $30^{\circ} \mathrm{C}$ for $7 \mathrm{~d}$.

\begin{tabular}{|c|c|c|c|c|c|}
\hline Volatile compound & $\begin{array}{l}\text { Putative } \\
\text { precursors(s) }\end{array}$ & Lactobacillus & Leuconostoc & Lactococcus & Enterococcus \\
\hline Isopropylpropionate & Ala & & & & $\mathrm{x}$ \\
\hline Propionic acid & Ala & $\mathrm{x}$ & $\mathrm{x}$ & $\mathrm{x}$ & $\mathrm{x}$ \\
\hline Ketobutyric acid & Glu & & $\mathrm{x}$ & & \\
\hline Acetic acid & Gly & $\mathrm{x}$ & $\mathrm{x}$ & $\mathrm{x}$ & $\mathrm{x}$ \\
\hline 2-Methyl-1-butanol & Ile & $\mathrm{x}$ & & & \\
\hline 3-Methyl-1-butanol & Leu & $\mathrm{x}$ & & & \\
\hline 3-Methylbutyric acid & Leu & & $\mathrm{x}$ & $\mathrm{x}$ & \\
\hline Dimethyl trisulfide & Met & $\mathrm{x}$ & $\mathrm{x}$ & & \\
\hline Benzaldehyde & Phe & $\mathrm{x}$ & & $\mathrm{x}$ & $\mathrm{x}$ \\
\hline Acetophenone & Phe & & $\mathrm{x}$ & $\mathrm{x}$ & $\mathrm{x}$ \\
\hline Benzoic acid & Phe & & $\mathrm{x}$ & & \\
\hline Benzophenone & Phe & & $\mathrm{x}$ & $\mathrm{x}$ & $\mathrm{x}$ \\
\hline Diphenylether & Phe/Tyr & & & $\mathrm{x}$ & $\mathrm{x}$ \\
\hline 2-Ethoxyethanol & Ser & & $\mathrm{x}$ & & \\
\hline 2-Ethoxyethoxy-2-ethanol & Ser & $\mathrm{x}$ & $\mathrm{x}$ & $\mathrm{x}$ & $\mathrm{x}$ \\
\hline Glycol & Ser & & $\mathrm{x}$ & $\mathrm{x}$ & $\mathrm{x}$ \\
\hline 2,3-Butanediol & Thr & & $\mathrm{x}$ & & $\mathrm{x}$ \\
\hline 1,2-Propanediol & Thr & & $\mathrm{x}$ & & \\
\hline Indole & $\operatorname{Trp}$ & $\mathrm{x}$ & $\mathrm{x}$ & & \\
\hline Phenol & Tyr & $\mathrm{x}$ & $\mathrm{x}$ & $\mathrm{x}$ & \\
\hline 2-Methyl-1-propanol & Val & & & $\mathrm{x}$ & $\mathrm{x}$ \\
\hline 2-Methylpropionic acid & Val & $\mathrm{x}$ & $\mathrm{x}$ & $\mathrm{x}$ & $\mathrm{x}$ \\
\hline Isopropyl isobutyrate & Val & & & $\mathrm{x}$ & $\mathrm{x}$ \\
\hline
\end{tabular}

$\mathrm{X}=$ present.

the result of our deliberate choice of a simplified, welldefined system to study a process (i.e., FAA catabolism) that is highly complex, so extrapolation to cheese should be done with care.

Leuconostoc strains are the most active in generation of volatiles; examples include $\alpha$-ketobutyric acid, benzoic acid, and 1,2-propanediol. The volatile patterns produced by the four genera of microorganisms reflect different enzyme activities, hence suggesting that they may follow distinct metabolic pathways to generate volatiles from a given precursor.

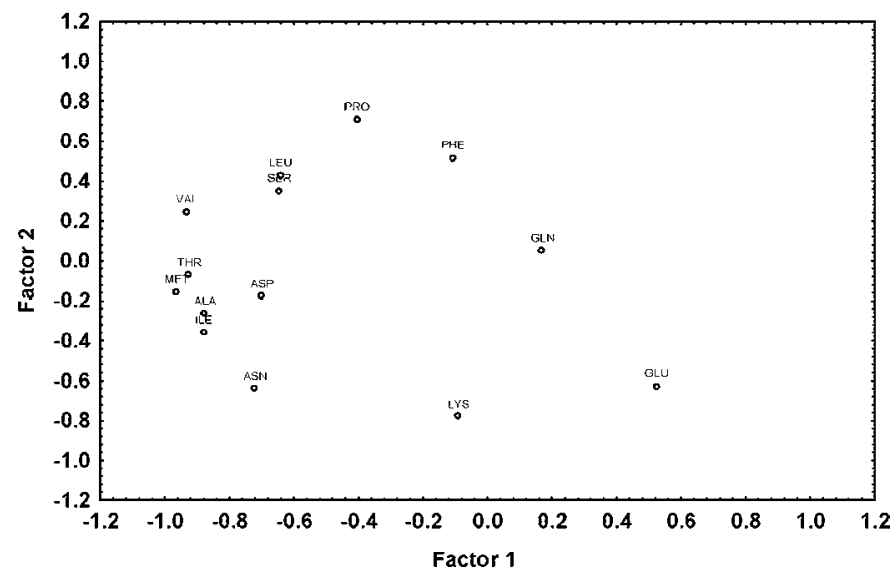

Figure 4. Principal component analysis plot, showing the free amino acid distribution for all samples along factors 1 and 2 .

\section{CONCLUSIONS}

With respect to individual FAA uptake, our experimental observations did not unfold clear relationships between those degraded preferentially by the strains tested and those most abundant in cheese. All microbial isolates exhibited a higher capacity to take up FAA at $\mathrm{pH} 6.0$ than at $\mathrm{pH} 4.5$ or 7.5 , thus suggesting that the optimum $\mathrm{pH}$ for most endocellular enzymes involved in the process should be ca. 6.0. However, the pattern of volatiles formed is greatly dependent on the genus in question, owing to the distinct enzyme machineries available. Furthermore, not all volatiles formed correlate well with disappearance of their (putative) FAA precursors.

Metabolism of all FAA together in solution by the strains tested correlates poorly with the concentrations of volatiles found in cheese; realization that solubility in a matrix containing fat globules may contribute to easier access to the active centers of hydrophobic enzymes might help explain (at least partially) such evidence. Furthermore, the higher complexity of the cheese matrix relative to well-defined, homogeneous solutions may dictate breakdown and generation of specific compounds, as a result of specific additional (or alternative) pathways. Among the strains tested, Leuconostoc spp. were the most active in terms of conversion of FAA to volatiles.

Upcoming studies should to advantage focus on the evaluation of the enzyme machinery of selected isolates 
upon each (and all) FAA, in order to map the anabolic pathways encompassing every volatile of interest. However, our study already suggests that the wild strains tested offer great potential as tentative nonstarter cultures for enhancing the aroma in Serra da Estrela (and similar) cheeses.

\section{ACKNOWLEDGMENTS}

The authors are grateful to the European Commission for partial funding through projects FAIR CT 973173 entitled Control, acceleration and diversification of cheese flavor formed by enzymatic conversion of AA, and MCFI-2000-02049 entitled TRADEOFF: TRAditional Dairy tEchnology tOward saFer Foods. Personal financial support for authors Dahl and Tavaria was provided by a Post-Doc fellowship (PRAXIS BPD-11838/ 97) and a Ph.D. fellowship (PRAXIS BD-9572/96), respectively, both granted by the Portuguese Government (Fundação para a Ciência e Tecnologia, PRAXIS XXI, Portugal).

\section{REFERENCES}

Barcina, Y., F. C. Ibáñez, and A. I. Ordónez. 1995. Evolution of free amino acids during Idiazábal cheese ripening. Food Control $6: 161-164$.

Bosset, J. O., and R. Gauch. 1993. Comparison of the volatile flavour compounds of six european "AOC" cheeses by using a new dynamic headspace GC-MS method. Int. Dairy J. 3:359-377.

Brendehaug, J., and T. Langsrud. 1985. Amino acid metabolism in Propionibacteria: resting cells experiments with four strains. J. Dairy Sci. 68:281-289.

Broome, M. C., D. A. Krause, and M. W. Hickey. 1990. The use of non-starter lactobacilli in Cheddar cheese manufacture. Aust. J. Dairy Technol. 45:67-73.

Chin, H. W., R. A. Bernhard, and M. Rosenberg. 1996. Solid phase microextraction for cheese volatile compound analysis. J. Food Sci. 61:1118-1121.

Christensen, K. R., and G. A. Reineccius. 1995. Aroma extract dilution analysis of aged Cheddar cheese. J. Food Sci. 60:218-220.

Dahl, S., F. K. Tavaria, and F. X. Malcata. 2000. Flavour and microbiological relationships in Serra da Estrela cheese during ripening. Int. Dairy J. 10:255-262.

Engels, W., and S. Visser. 1994. Isolation and comparative characterization of components that contribute to the flavour of different types of cheese. Neth. Milk Dairy J. 48:127-140.

Esteban, J. L., I. Martínez-Castro, R. Morales, B. Fabrellas, and J. Sanz. 1996. Rapid identification of volatile compounds in aromatic plants by automatic thermal desorption-GC-MS. Chromatographia 43:63-72.
Folkertsma, B., and P. F. Fox. 1992. Use of Cd-ninhydrin reagent to assess proteolysis in cheese during ripening. J. Dairy Res. $59: 217-224$

Fox, P. F., and J. Law. 1991. Enzymology of cheese ripening. Food Biotechnol. 5:239-262.

Fox, P. F., and J. M. Wallace. 1997. Formation of flavour compounds in cheese. Adv. Appl. Microbiol. 45:17-85.

Freitas, A. C., J. M. Fresno, B. Prieto, I. Franco, F. X. Malcata, and J. Carballo. 1998. Influence of milk source and ripening time on free amino acid profile of Picante cheese. Food Control 9:187-194.

Gummalla, S., and J. Broadbent. 1999. Tryptophan catabolism by Lactobacillus casei and Lactobacillus helveticus cheese flavor adjuncts. J. Dairy Sci. 82:2070-2077.

Jackman, P. 1985. Bacterial taxonomy based on electrophoretic whole-cell protein patterns. In Chemical Methods in Bacterial Systematics. Ed. Goodfellow, M. and D. E. Minnikin, pp.188-308. London: Academic Press.

Kersters, K. 1985. Numerical methods in the classification of bacteria by protein electrophoresis. In Computer Assisted Numerical Systematics. Ed. M., Goodfellow, D. Jones, and F. G. Priest, pp. 337368. London: Academic Press.

Lee, C.-W., and J. Richard. 1984. Catabolism of L-phenylalanine by some microorganisms of cheese origin. J. Dairy Res. 51:461-469.

Macedo, A. C., F. X. Malcata, and T. A. Hogg. 1995. Microbiological profile in Serra ewe's cheese during ripening. J. Appl. Bacteriol. 79:1-11.

Molimard, P., and H. E. Spinnler. 1996. Review: Compounds involved in the flavor of surface mold-ripened cheeses: Origins and properties. J. Dairy Sci. 79:169-184.

Ordónez, J. A., and J. Burgos. 1980. Free amino acids of Manchego cheese ripened in olive oil. Milchwissenschaft 35:69-71.

Sousa, M. J., and F. X. Malcata. 1998. Comparison of plant and animal rennets in terms of microbiological, chemical and proteolysis characteristics of ovine cheese. J. Agric. Food Chem. 46:4034-4041.

StatSoft (1996). Statistica for Windows. Release 5.1. StatSoft, Tulsa, OK, USA.

Tammam, J. D., A. G. Williams, J. Noble, and D. Lloyd. 2000. Amino acid fermentation in non-starter Lactobacillus spp. isolated from Cheddar cheese. Lett. Appl. Microbiol. 30:370-374.

Tavaria, F. K., and F. X. Malcata. 1998. Microbiological characterization of Serra de Estrela cheese throughout its Appélation d'Origine Protégée region. J. Food Prot. 61:601-607.

Urbach, G. 1995. Contribution of lactic acid bacteria to flavour compound formation in dairy products. Int. Dairy J. 5:877-903.

Wallace, J. M., and P. F. Fox. 1997. Formation of flavour compounds in cheese. Adv. Appl. Microbiol. 45:17-85.

Wood, A. F., J. W. Aston, and G. K. Douglas. 1985. The determination of free amino acids in cheese by capillary column gas liquid chromatography. Aust. J. Dairy Technol. 40:166-169.

Yvon, M., S. Berthelot, and J. C. Gripon. 1998. Adding $\alpha$-ketoglutarate to semi-hard cheese curd highly enhances the conversion of amino acids to aroma compounds. Int. Dairy J. 8:889-898.

Yvon, M. S., Thirouin, L. Rijnen, D. Fromentier, and J. C. Gripon. 1997. An aminotransferase from Lactococcus lactis initiates conversion of amino acids to cheese flavor compounds. Appl. Environ. Microb. 63:414-419. 